\title{
Determination of heavy metals and pesticide residues level in selected sundried and smoked vegetables from Aizawl market
}

\author{
C. Malsawmtluangi*, B. Lalzamliana, Klaudi K. Vaiphei \\ Department of Pharmacy, Regional Institute of Paramedical and Nursing Sciences (RIPANS), Aizawl 796or7, India
}

\begin{abstract}
Sundried and smoked vegetables constitute major parts of the Mizo cuisine. Heavy metals and pesticides can be present in vegetables and cause many diseases including cancer. The objective of this study is to determine the concentration of heavy metal and pesticide residues in commonly consumed sundried and smoked vegetables from Aizawl market. Since cancer is prevailing at a high rate in Mizoram, it also aims to study whether there is any link between cancer and these vegetables. The concentrations of heavy metals were analyzed using atomic absorption spectroscopy and pesticide residues levels were analyzed using gas chromatography. This study reveals that the levels of heavy metals tested were within the permissible limits in all the vegetable samples, except for cadmium. Since cadmium exceeds the permissible limit, it can pose health risk for the consumers. The pesticide residues found in the tested samples were all within permissible limits. However, the amount and duration of consumption need to be considered as this can be a predisposing factor for cancer and other diseases.
\end{abstract}

Key words: Atomic absorption spectroscopy; cancer; gas chromatography; heavy metals; pesticides; sundried and smoked vegetables.

\section{Introduction}

Heavy metals and pesticides are persistent and non-biodegradable chemical compounds and they can be bio-accumulated through the biologic chains such assoil-plant-food and seawater-marine organism-food. Their accumulation in human vital organs can cause varying degree of illness on acute and chronic exposure. For this reason, accurate monitoring of their concentration plays an important role. Food safety is a major public concern worldwide. The increasing demand of food safety has stimulated research regarding the risk associated with consumption of foodstuffs contaminated by pesticides, heavy metals and/or toxins. ${ }^{1,2}$

Plants and vegetables are the main links in the transfer of heavy metals from the contaminated soil to humans. Heavy metals have low excretion rates through the kidney which could result in damaging effects on humans even at very low concentrations. Metals such as zinc, copper, iron, manganese, and chromium are essential nutrients; they are important for the physiological and biological functions of the human body. However, an increase in their intake above certain permissible limits can become 
toxic. ${ }^{3}$ The excess of heavy metals in human bodies can cause anemia, kidney damage, lung disease (e.g. bronchitis and pulmonary oedema), nervous system disorders, hyperactivity, hypertension, behavioral changes, infertility to male, cancers (e.g. lung, prostate, and kidney), and even cause death. ${ }^{4,5}$

The ever-growing market demand had forced the cultivators to use various pesticides to meet the demands. Farmers use pesticides as a preventive policy against the possibility of a devastating crop loss from pests and diseases. This has led to an increasing health concern as pesticides contain various harmful chemicals for humans and animals. The toxic effect observed in human includes disorders in the male and female reproductive system, infertility, carcinogenicity, developmental toxicity, neurotoxicity and immunotoxicity ${ }^{6,7}$

Sundried and smoked vegetables constitute a high portion of vegetables intake in Mizoram. Some vegetables are available abundantly only in rainy season and scarce during the dry season. Therefore, drying (sundried/smoked) of these vegetables is commonly done to preserve them. Cancer is prevailing at a high rate in Mizoram and the Mizo diet consists of lots of sundried and smoked vegetables as indispensable components in food. Since heavy metals and pesticides are known carcinogens, ${ }^{8,9}$ and, therefore, is important to reveal the clear picture of the link between cancer and smoked/dried vegetables. Keeping in view of the potential toxicity, persistent nature and cumulative behavior of heavy metals and pesticides as well as the consumption of smoked/dried vegetables, there is a necessity to test and analyze these food items to ensure that the levels of these contaminants meet the international permissible limits. So, this study aims to analyze and determine the level of some heavy metals and pesticides which contaminate our vegetables in Mizoram.

\section{Materials and Methods}

\section{Sample collection}

To determine the heavy metals and residues of different pesticides in selected sundried and smoked vegetables, samples were collected from Aizawl markets. Selected vegetable samples are given in Table 1.

\section{Chemicals and reagents}

Heavy metals standard solutions - arsenic (As), cadmium (Cd), chromium ( $\mathrm{Cr}$ ), copper ( $\mathrm{Cu}$ ) and zinc ( $\mathrm{Zn})$; pesticides standard solutions alpha-BHC, gamma-BHC, beta-BHC, heptachlor, aldrin, heptachlor epoxide, dieldrin, endrin, 2, 4'-DDD, 4, 4'-DDD, 2, 4'-DDT, 4, 4'-DDT, 4, 4'DDE; nitric acid, anhydrous sodium sulphate, activated charcoal, acetone, n-hexane, silica gel 60-120 mesh. All the chemicals used are of analytical grade.

\section{Determination of heavy metals ${ }^{\top}$}

The samples were ground into powder form by using digital grinder. $1 \mathrm{~g}$ of each sample was weighed, mixed with $8 \mathrm{ml}$ nitric acid. The mix-

Table 1 | Selected smoked and sundried vegetables for analysis.

\begin{tabular}{|c|c|c|c|}
\hline No & Sample & Scientific Name & Local name \\
\hline 1. & Sundried kenaf leaves & Hibiscus cannabinus & Anthur rep \\
\hline 2. & Smoked kenaf leaves & Hibiscus cannabinus & Anthur rap rep \\
\hline 3. & Sundried cowpea leaves & Vigna unguilata L. Walp. & Behlawi rep \\
\hline 4. & Smoked cowpea leaves & Vigna unguilata L. Walp. & Behlawi rap rep \\
\hline 5. & Smoked black mustard leaves & Brassica nigra & Anțam rap rep \\
\hline 6. & Dried fermented black mustard leaves & Brassica nigra & Ṭam-um \\
\hline 7. & Smoked taro leaves & Colocasia esculenta & Dawlțawm \\
\hline 8. & Sundried bamboo shoot & Melocanna baccifera & Mautuai rep \\
\hline 9. & Sundried snowflake tree buds & Trevesia palmata & Kawhtebel rep \\
\hline
\end{tabular}


ture was then digested in the microwave digester until the solution became transparent. The digested sample was adjusted up to $100 \mathrm{ml}$ in a volumetric flask with distilled water; the resulting solution was filtered through Whatman filter paper. The samples were cooled to a room temperature within the tubes and were analyzed for concentrations of $\mathrm{As}, \mathrm{Cd}, \mathrm{Cr}$, $\mathrm{Cu}$ and $\mathrm{Zn}$ in air-acetylene and air-acetyleneargon flame by atomic absorption spectroscopy (iCE 3000 Series, Thermo Scientific).

\section{Determination of pesticide residues level ${ }^{10}$}

Sampling and Pesticides Extraction: $15 \mathrm{~g}$ of anhydrous sodium sulphate was placed in a funnel and $30 \mathrm{ml}$ of the liquid sample was passed through to absorb water content in the sample. $20 \mathrm{~g}$ of the powder sample was ground with $10 \mathrm{~g}$ of anhydrous sodium sulphate to absorb the water content. The sample was extracted with 50 $\mathrm{ml}$ acetone by mechanically shaking for 1 hour. The extract was then filtered. The extracted filtrate was concentrated to $25 \mathrm{ml}$ using a water bath and was subjected to liquid-liquid partitioning with $\mathrm{n}$-hexane in separating funnel. The n-hexane layer containing pesticide residue was collected passing through sodium sulphate to remove traces of water content. The aqueous phase was subjected to hexane extraction three times for leftover residues. The pooled hexane fraction was concentrated to $10 \mathrm{ml}$.

Sample Extract Clean-Up: The pigments were removed by passing through a glass column containing activated charcoal and anhydrous sodium sulphate. Then, silica gel column chromatography was performed to remove other interfering aliphatic and polar compounds. Briefly, glass column (300 mm X $10 \mathrm{~mm}$ ) was packed from bottom to up with clean glass wool, $10 \mathrm{~g}$ activated silica gel, and $2.5 \mathrm{~g}$ anhydrous sodium sulphate. The column was pre-rinsed with $50 \mathrm{ml} \mathrm{n}$-hexane before the sample was loaded, then the sample was loaded with three rinsing of extract flask with $2 \mathrm{ml}$ hexane. The elution of analytes was subsequently carried out using 100 $\mathrm{ml}$ hexane and concentrated to $2.0 \mathrm{ml}$. The extract was transferred to an autosampler vial and sealed for qualification using gas chromatography equipped with an electron capture detector (GC-ECD).

Pesticide Analysis and Quantification: Identification and quantification of organochlorine pesticides were carried out using Gas Chromatograph (Thermo Trace GC 800) equipped with 63Ni-ECD. Separation of pesticides was done on a TR-1701 capillary column. The detector temperature was maintained at $300^{\circ} \mathrm{C}$ and

Table 2 | Heavy metals concentration in selected sundried and smoked vegetables with FAO/WHO permissible values.

\begin{tabular}{|c|c|c|c|c|c|c|}
\hline \multirow{2}{*}{ No. } & \multirow[b]{2}{*}{ SAMPLES } & \multicolumn{5}{|c|}{ Heavy metals concentration $(\mathrm{mg} / \mathrm{kg})$} \\
\hline & & $\begin{array}{l}\text { Arsenic } \\
\text { (mg/kg) }\end{array}$ & $\begin{array}{l}\text { Cadmium } \\
(\mathrm{mg} / \mathrm{kg})\end{array}$ & $\begin{array}{l}\text { Chromium } \\
\text { (mg/kg) }\end{array}$ & $\begin{array}{l}\text { Copper } \\
\text { (mg/kg) }\end{array}$ & $\begin{array}{c}\text { Zinc } \\
(\mathrm{mg} / \mathrm{kg})\end{array}$ \\
\hline 1. & Sundried kenaf leaves & $0.028 \pm 0.02$ & $0.415 \pm 0.04 *$ & $0.346 \pm 0.06$ & $0.082 \pm 0.01$ & $0.305 \pm 0.03$ \\
\hline 2. & Smoked kenaf leaves & $0.026 \pm 0.09$ & $0.418 \pm 0.10 *$ & $0.400 \pm 0.04$ & $0.158 \pm 0.02$ & $0.151 \pm 0.05$ \\
\hline 3. & Sundried cowpea leaves & $0.033 \pm 0.08$ & $0.415 \pm 0.11 *$ & $0.366 \pm 0.07$ & $0.114 \pm 0.06$ & $0.159 \pm 0.08$ \\
\hline 4. & Smoked cowpea leaves & $0.031 \pm 0.12$ & $0.414 \pm 0.12 *$ & $0.371 \pm 0.03$ & $0.096 \pm 0.12$ & $0.034 \pm 0.09$ \\
\hline 5. & Smoked black mustard leaves & $0.036 \pm 0.05$ & $0.414 \pm 0.05^{*}$ & $0.376 \pm 0.12$ & $0.112 \pm 0.09$ & $0.426 \pm 0.11$ \\
\hline 6. & Dried fermented black mustard leaves & $0.036 \pm 0.07$ & $0.417 \pm 0.12 *$ & $0.313 \pm 0.08$ & $0.112 \pm 0.14$ & $5.595 \pm 0.12$ \\
\hline 7. & Smoked taro leaves & $0.022 \pm 0.04$ & $0.417 \pm 0.14 *$ & $0.374 \pm 0.15$ & $0.066 \pm 0.06$ & $0.165 \pm 0.09$ \\
\hline 8. & Sundried bamboo shoot & $0.030 \pm 0.09$ & $0.415 \pm 0.13^{*}$ & $0.386 \pm 0.07$ & $0.111 \pm 0.12$ & $1.384 \pm 0.09$ \\
\hline 9. & Sundried snowflake tree buds & $0.033 \pm 0.16$ & $0.416 \pm 0.15^{*}$ & $0.358 \pm 0.09$ & $0.063 \pm 0.06$ & $0.123 \pm 0.05$ \\
\hline 10. & FAO/WHO permissible limits (mg/kg)a & $0.10^{c}$ & $0.20^{\mathrm{a}}$ & $2.3^{\mathrm{a}}$ & $40^{\mathrm{a}}$ & $100^{\mathrm{a}}$ \\
\hline
\end{tabular}

All values are expressed as mean \pm SD for 3 samples (SD $=$ Standard deviation).

* indicates the level of heavy metal concentration more than the permissible level of WHO and FAO.

${ }^{\mathrm{a}} \mathrm{FAO} / \mathrm{WHO}$ (2001), Joint Codex Alimentarius Commission.

'Permissible limits (FAO/WHO 1999) of the metals. 
the injector temperature was maintained at $200^{\circ}$ C. Nitrogen was used as a carrier gas at a flow rate of $2 \mathrm{ml} / \mathrm{min}$. Detection was carried out using electron capture detector. The flow parameter was set as MK-N2ml:30. $1 \mu \mathrm{l}$ of the sample was injected and the chromatogram obtained was compared with the calibrated external reference standard chromatogram.

\section{Results and Discussion}

Samples were analysed for heavy metals such as As, Cd, $\mathrm{Cr}, \mathrm{Cu}$ and $\mathrm{Zn}$ and compared with that of the FAO/WHO permissible limits. All the heavy metals tested were detected in all the samples and their concentrations are given in Table 2. The concentration of arsenic, chromium, copper and zinc present in the samples were lower than the FAO/WHO maximum permissible limits except for cadmium.

The concentrations of $\mathrm{Cd}$ in the samples were found in the range of $0.414-0.418 \mathrm{mg} / \mathrm{kg}$, the highest concentration being found in smoked kenaf leaves. According to WHO/FAO, the maximum permissible limit for $C d$ is $0.2 \mathrm{mg} /$ $\mathrm{kg}$ (FAO/WHO, Joint Codex Alimentarius Commission, 2001). ${ }^{11,12}$ Since Cadmium exceeds the permissible limit, it may pose a health risk for the consumer. Cadmium is very toxic, its longterm exposure to lower levels leads to a build up in the kidneys and possible kidney disease, lung damage, and fragile bones. Hypertension, arthritis, diabetes, anemia, cancer, cardiovascular disease, cirrhosis, reduced fertility, hypoglycemia, headaches, osteoporosis, kidney disease, and strokes are its long term effects. ${ }^{12}$

The levels of zinc in the samples were found in the range of 0.034 and $5.595 \mathrm{mg} / \mathrm{kg}$, which is below the maximum permissible value, i.e. 100 $\mathrm{mg} / \mathrm{kg}$ (FAO/WHO (2001), Joint Codex Alimentarius Commission. ${ }^{13}$ But according to Ogunkunle et al. the permissible limit of zinc was 1.5 $\mathrm{mg} / \mathrm{kg}$ (WHO, 1999). ${ }^{14}$ Among all metals, zinc is the least toxic and an essential element in the human diet as it is required to maintain the proper functions of the immune system. However the high concentration of zinc may be toxic to the body. ${ }^{15}$
Arsenic is extremely toxic. The concentration of arsenic exceeding the maximum permissible limit is 0.1 (FAO/WHO 1999) which can cause short term (nausea, vomiting, diarrhea, weakness, loss of appetite, cough and headache) and long term (cardiovascular diseases, diabetes and vascular diseases) health effects. ${ }^{16}$ Results show that the maximum concentration of arsenic is found in smoked black mustard leaves and dried fermented black mustard leaves but they are within or lower than the permissible limits. kg

All the vegetable samples had lower levels of $\mathrm{Cu}$ than the maximum permissible values, i.e. 40 $\mathrm{mg} / \mathrm{kg}$ recommended by the FAO/ WHO.11 Our result shows the concentration of copper $(\mathrm{Cu})$ in the range of 0.066 and $0.158 \mathrm{mg} / \mathrm{kg}$, the highest concentration being found in smoked kenaf leaves. Chromium level is in the range of 0.313 and $0.400 \mathrm{mg} / \mathrm{kg}$ which is lower than the permissible level, i.e. 2.3 (FAO/WHO-(2001), Joint Codex Alimentarius Commission. .112 $^{12}$

Pesticides are dangerous to human health if it exceeds the calculated maximum residue limit. Due to the spraying of pesticides on vegetables, it leaves their residues. ${ }^{17}$ The concentration of pesticides detected in the samples are shown in Table 3. Among the pesticides tested, 4, 4' DDT, 2, 4' DDD, 4, 4' DDD, alpha-BHC, aldrin, endrin and dieldrin were not detected in any of the samples (Table 3 ). The pesticide residues found in all the tested samples were lower than the maximum residual limit according to CODEX Alimentarius Commission ${ }^{18}$ (Table 4).

The pesticides detected were heptachlor, 4, 4'-DDE, heptachlor epoxide, 2, 4'-DDT, gamma$\mathrm{BHC}$ and beta-BHC. heptachlor and 4, 4'-DDE were detected in 6 of the samples in the range of 0.001 to $0.004 \mathrm{mg} / \mathrm{kg}$ and 0.001 to $0.002 \mathrm{mg} / \mathrm{kg}$ respectively. Heptachlor epoxide, 2, 4'- DDT, gamma-BHC and beta-BHC were detected in 1 sample each. No pesticide residue was detected in Smoked kenaf leaves.

The results of the present study shows that tested vegetables were subjected to contamination of the environment by heavy metals and pesticides. Pesticides and heavy metals detected (except cadmium) are within the permissible limits of WHO and FAO. Thus, the consumption 


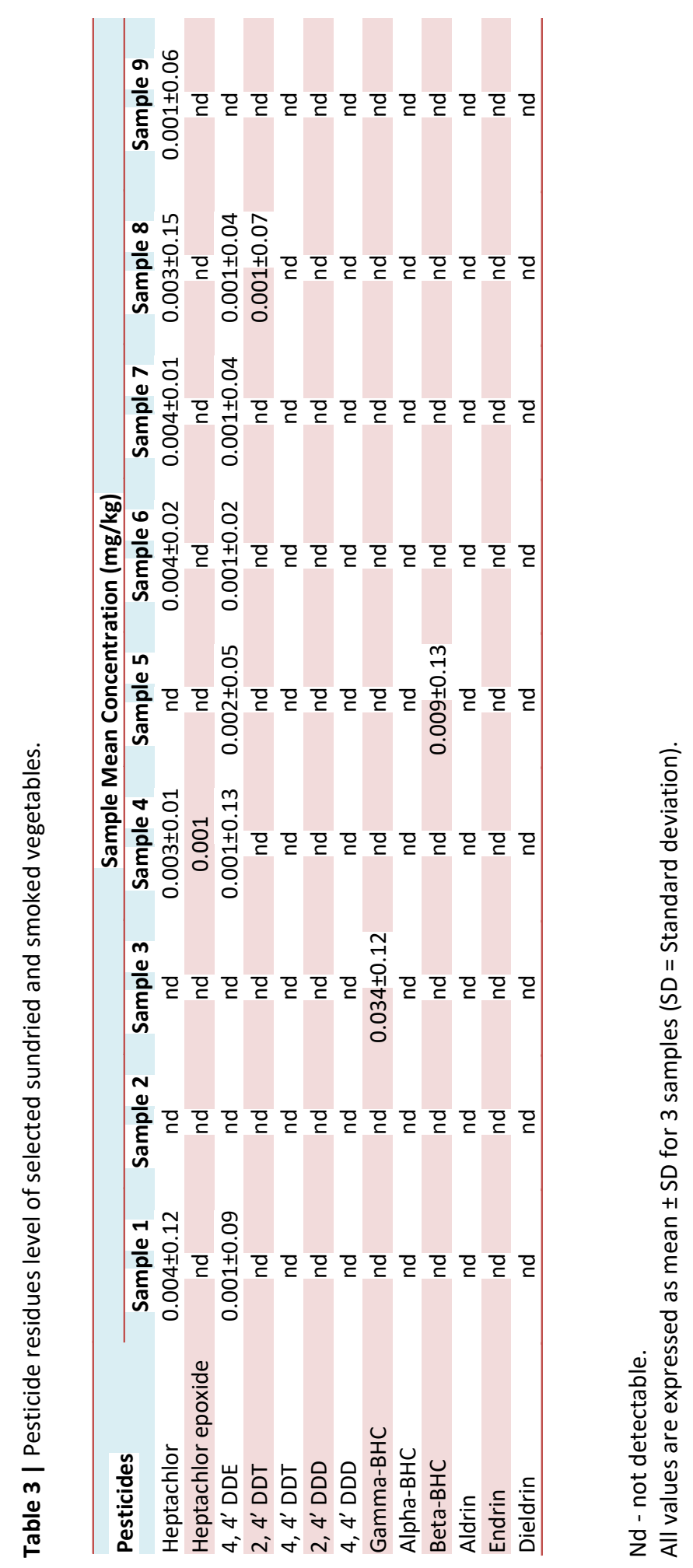


Table 4 | Comparison of pesticide residues level of selected sundried and smoked vegetables with the international limit (CODEX).

\begin{tabular}{|c|c|c|c|c|}
\hline No. & Sample & Pesticides detected & $\begin{array}{c}\text { Mean concentration } \\
(\mathrm{mg} / \mathrm{Kg})\end{array}$ & $\begin{array}{c}\text { Permissible } \\
\text { limits (mg/Kg) }\end{array}$ \\
\hline \multirow[t]{2}{*}{1} & Sundried kenaf leaves & Heptachlor & 0.004 & 0.05 \\
\hline & & 4, 4' DDE & 0.001 & 1.0 \\
\hline 2 & Smoked kenaf leaves & No identified compound(s) & & \\
\hline 3 & Sundried cowpea leaves & Gamma BHC & 0.034 & 0.6 \\
\hline \multirow[t]{3}{*}{4} & Smoked cowpea leaves & Heptachlor & 0.003 & 0.05 \\
\hline & & Heptachlor epoxide & 0.001 & 0.05 \\
\hline & & 4, 4' DDE & 0.001 & 1.0 \\
\hline \multirow[t]{2}{*}{5} & Smoked black mustard leaves & Beta BHC & 0.009 & 0.3 \\
\hline & & 4, 4' DDE & 0.002 & 1.0 \\
\hline \multirow[t]{2}{*}{6} & Dried fermented black mustard leaves & Heptachlor & 0.004 & 0.05 \\
\hline & & 4, 4' DDE & 0.001 & 1.0 \\
\hline \multirow[t]{2}{*}{7} & Smoked taro leaves & Heptachlor & 0.004 & 0.05 \\
\hline & & 4, 4' DDE & 0.001 & 1.0 \\
\hline \multirow[t]{3}{*}{8} & Sundried bamboo shoot & Heptachlor & 0.003 & 0.05 \\
\hline & & 4, 4' DDE & 0.001 & 1.0 \\
\hline & & $2,4^{\prime} \mathrm{DDT}$ & 0.001 & 0.2 \\
\hline 9 & Sundried snowflake tree buds & Heptachlor & 0.001 & 0.05 \\
\hline
\end{tabular}

of average amounts of these sundried and smoked vegetables may not be considered a critical issue. However, these compounds are resistant to degradation, ${ }^{9}$ so, the amount and duration of consumption need to be considered as this can be a predisposing factor for cancer and other diseases.

\section{Acknowledgement}

The Authors thankfully acknowledge the Department of Pharmacy, RIPANS, Aizawl, Mizoram for providing all the necessary facilities to complete this study.

\section{References}

I. Bempah, C.K., Buah-Kwofie, A., Tutu, A.O., Denutsui, D., Enimil, E., Adjei-Martey, G., Blewu, B. \& Asomaning, J. (20II). Pesticide residues and heavy metals levels in some selected fruits and vegetables from Ghanaian markets. Elixir Food Science 39, 4964-4972.

2. Asdeo, A. \& Loonkar, S. (20II). A competitive analysis of trace metals in vegetables. Research Journal of Environmental Toxicology 5 (2), 125-132.

3. Dghaim, R., Khatib, S.A., Rasool, H., \& Khan, M.A.
(20I5). Determination of heavy metals concentration in traditional herbs commonly consumed in the United Arab Emirates. Journal of Environmental and Public Health I (I), I-6.

4. Hodgson, E. (2010). Classes of Toxicants: Use Classes. In Textbook of Modern Toxicology, North Carolina State University Raleigh, North Carolina, USA, pp. 4956.

5. Siaka, M., Utama, M.S., Manuaba, B.P. \& Adnyana, M. (2014). Heavy metals contents in the edible parts of some vegetables grown in Candi Kuning, Bali and their predicted pollution in the cultivated soil. Journal of Environment and Earth Science 4, 78-83.

6. Hussaina, Z. \& Siddiqueb, S. (2010). Determination of pesticides in fruits and vegetables using acetonitrile extraction and GC/MS technique. Journal of Scientific Research 40, 19-30.

7. Chowdhury, M.A.Z., Fakhruddin, A.N.M., Islam, M.N., Moniruzzaman, M., Gan, S.H. \& Alam, M. K. (2013). Detection of the residues of nineteen pesticides in fresh vegetable samples using gas chromatographymass spectrometry. Food Control 34, 457-465.

8. Radwan, M.A., Salam,a A.K. (2006). Market basket survey for some heavy metals in Egyptian fruits and vegetables. Food and Chemical Toxicology 44, I273-1278.

9. Ozcan, C. (2016). Determination of organochlorine pesticides in some vegetable samples using GC-MS. 
Polish Journal of Enviromental. Studies 25, II4I-II47.

ro. Kumar, B., Kumar, S., Mishra, M., Prakash, D., Singh, K.S. \& Sharma, S.C. (2OI2). Persistent chlorinated pesticide residues in selected market vegetables of root and leaf origin. Asian Journal of Plant Science and Research 2, 232-236.

II. Maleki, A. \& Zarasvand, M.A. (2008). Heavy metals in selected edible vegetables and estimation of their daily intake in Sanandaj, Iran. Southeast Asian Journal of Tropical Medicine and Public Health 39, 335-340.

I2. Lokeshappa, B., Shivpuri, K., Tripathi, V., \& Dikshit, A.K. (2OI2). Assessment of Toxic Metals in Agricultural Produce. Food and Public Health 2, 24-29.

13. Mohod, C.V. (2005). A Review on the Concentration of the heavy metals in vegetable samples like spinach and tomato grown near the area of Amba Nalla of Amravati City. International Journal of Innovative Research in Science, Engineering and Technology 4, 2788-2792.
I4. Ogunkunle, A. T. J., Bello, O.S. \& Ojofeitimi, O.S. (2014). Determination of heavy metal contamination of street-vended fruits and vegetables in Lagos state, Nigeria, International Food Research Journal 2I, 2II5-2I2O.

I5. Kumar, N., Soni, H. \& Kumar, R.N. (2007). Characterization of heavy metals in vegetables using inductive coupled plasma analyzer (ICPA). Journal of Applied Sciences and Environmental Management II,75 - 79.

I6. Abbas, M., Parveen, Z., Iqbal, M., Riazuddin, Iqbal, S., Ahmed, M. \& Bhutto, R. (2010). Monitoring of toxic metals (cadmium, lead, arsenic and mercury) in vegetables of Sindh, Pakistan. Kathmandu University Journal of Science, Engineering and Technology 6, 6o-65.

17. Munawar, A., Hameed, S.W. (2013). Quantification of pesticide residues in vegetables by different chromatographic techniques. Journal of Chromatography $\mathcal{E}$ Separation Techniques 4, 1000200.

I8. WHO (2007). WHO Guidelines for Assessing Quality of Herbal Medicines with Reference to Contaminants and Residues. WHO, Geneva, Switzerland, pp. 27-29. 